\title{
Smart households: Dispatch strategies and economic analysis of distributed energy storage for residential peak shaving
}

\section{Main manuscript}

\author{
Menglian Zheng, ${ }^{\mathrm{a}, *}$, Christoph J. Meinrenken ${ }^{\mathrm{a}}$, and Klaus S. Lackner ${ }^{\mathrm{a}, \mathrm{b}}$ \\ ${ }^{a}$ Lenfest Center for Sustainable Energy, Earth Institute \\ Department of Earth and Environmental Engineering \\ Columbia University \\ $500 \mathrm{~W} 120^{\text {th }}$ Street, Mudd 918 \\ New York, NY 10027, USA \\ mz2321@columbia.edu \\ ${ }^{\mathrm{b}}$ Center for Negative Carbon Emissions \\ School of Sustainable Engineering and the Built Environment \\ Ira A. Fulton Schools of Engineering \\ Arizona State University
}


Zheng et al. - APEN-D-14-05563R1 - Manuscript (no changes marked) - Page 2 of 23

Highlights (3-5 bullets, max. 85 characters (incl. spaces) per bullet point)

- Cost-effectiveness of building-based storage for peak shaving has hitherto not been well understood

- Several existing storage technologies are shown to provide cost-effective peak shaving

- Setting grid demand targets rather than hard demand limits improves economics

- Accounting for seasonal demand variations in storage dispatch strategy improves economics further

- Total-energy-throughput approach is used to determine storage lifetimes

\begin{abstract}
Meeting time-varying peak demand poses a key challenge to the U.S. electricity system. Building-based electricity storage - to enable demand response (DR) without curtailing actual appliance usage - offers potential benefits of lower electricity production cost, lower greenhouse gas footprint, and more flexibility to integrate renewables. DR tariffs are currently available in the U.S. but building-based storage is still underutilized due to insufficiently understood cost-effectiveness and dispatch strategies. Whether DR schemes can yield a profit for building operators (i.e., reduction in electricity bill that exceeds levelized storage cost) and which particular storage technology yields the highest profit is yet to be answered. This study aims to evaluate the economics of providing peak shaving DR under a realistic tariff (Con Edison, New York), using a range of storage technologies (conventional and advanced batteries, flywheel, magnetic storage, pumped hydro, compressed air, and capacitors). An agent-based stochastic model is used to randomly generate appliance-level demand profiles for an average U.S. household. We first introduce a levelized storage cost model which is based on a total-energy-throughput lifetime. We then develop a storage dispatch strategy which optimizes the storage capacity and the demand limit on the grid. We find that (i) several storage technologies provide profitable DR; (ii) annual profit from such DR can range from 1\% to 39\% of the household's non-DR electricity bill; (iii) allowing occasional breaches of the intended demand limit increases profit; and (iv) a dispatch strategy that accounts for demand variations across seasons increases profit further. We expect that a more advanced dispatch strategy with embedded weather forecasting could yield even higher profit.
\end{abstract}

Keywords (max. 6)

Demand response; Smartgrid; Electricity storage; Batteries; Peak shaving; Agent-based model 
Zheng et al. - APEN-D-14-05563R1 - Manuscript (no changes marked) - Page $\mathbf{3}$ of 23

\section{Introduction}

Meeting time-varying peak demand poses a key challenge to the U.S. electricity system [1]. This contributes to blackouts and brownouts that affect millions of consumers and cost American businesses more than US\$ 150 billion in an average year [2,3]. Peak demand is typically met by peak generators. This can lead to an overall increase in electricity production cost, through multiple mechanisms: Peak generators typically have higher marginal cost (e.g., older coal plants) or are based on technology with above-average operational flexibilities (e.g., gas, hydroelectric units) [3]. Low capacity utilization creates significant hurdles for peak generators to return a profit on capital investments [4]. Facing low returns from peak generators despite ever increasing peak demand, merchant generators are reluctant to build new peak generation facilities and instead delay the retirement of older, usually more inefficient, and hence costlier plants (e.g., [5]). As another disadvantage of peak generators, inefficient plants increase greenhouse gas (GHG) emissions and other air pollutant emissions per unit of electricity produced [2].

As an alternative method to alleviate above problems, demand response (DR) lowers electricity use "at times of high wholesale market prices or when system reliability is jeopardized from the demand side"[6]. DR thus alleviates grid stress from the demand side. Over the past decades, economics and operating performance of electricity storage technologies have improved [3, 7-12]. DR with storage provides new opportunities to enable DR without curtailing actual appliance usage [13]. Compared with large-scale, grid-based storage, DR via small-scale, distributed storage in residential, commercial, or industrial settings provides more flexibilities [14] and will likely facilitate integration of building-based intermittent renewables(e.g., [15]). A variety of DR programs, such as load shifting, peak shaving, spinning reserve, frequency regulation, etc., have been discussed in extensive studies (e.g., [16, 17]). However, in the U.S., today's existing DR programs represent less than $25 \%$ of the total market potential for DR $[18,19]$. Barriers still exist: The lack of in-depth understanding of the cost-effectiveness of storage and the lack of practical dispatch strategies delay wider adoption of DR $[3,20]$.

In prior work, based on the time-of-use (TOU) energy tariff available from Consolidated Edison Company of New York, Inc. (henceforth "Con Edison"), a dispatch strategy was developed to time-shift energy requirements (i.e., $\mathrm{kWh}$ ) from peak periods to off peak periods [21], also referred to as loadshifting. In contrast to this earlier work, the focus of the present study is to use electricity storage with the focus on reducing peak power (i.e., kW) demands (e.g., [22]), thus smoothing demand profiles (Fig. 1). This is commonly referred to as peak shaving. Both studies focus on residential DR.

Unlike loadshifting strategies, which normally cycle storage only once per day, peak shaving strategies under demand tariffs require more complex (dis-)charge patterns, for several reasons: Firstly, demand tariffs typically include a facility or anytime demand charge denominated in $\$$ per $\mathrm{kW}$. This charges maximum demand during a one-month billing period regardless of when the demand occurs, including at night when a loadshifting strategy would otherwise charge storage [17]. This facility demand charge is designed to reflect the cost of the capacity of the electricity infrastructure needed to generate, transmit, and distribute electric energy to consumers [17]. Secondly, demand tariffs typically have a separate energy charge (in $\$$ per $\mathrm{kWh}$ ) that comprise a significant portion ( 25\%) of the total tariff charge (Fig. 6). Therefore, an optimal dispatch strategy of the storage device will have to account for tradeoffs between two goals: (i) Lowering the demand charge by diverting peak demands of the building's appliances to the storage device; and (ii) the increased energy charge resulting from roundtrip (dis-)charge losses of the 
storage device. Thirdly, again in contrast to a loadshifting strategy, the strategy must optimize not only the storage capacity but also the building's demand limit above which the control unit (Fig. 1) will attempt to use stored electricity in addition to grid electricity to satisfy appliance demand. Therefore, any optimization for maximum profit has to address both storage capacity and demand limit (2-dimensional rather than 1 dimensional optimization). Lastly, shaving multiple demand peaks per day requires multiple (dis-)charge cycles, which influences the storage lifetime and thus the levelized storage cost (LSC).

For peak shaving DR applications, the present study advances previous studies that deal with some aspects of economically optimized DR: Dlamini et al. developed peak shaving strategies for residential consumers without using storage [23]. To reduce peak demand, some authors suggested interrupting appliance usage $[22,23]$, and Leadbetter and Swan proposed installing electricity storage devices in residential buildings. Leadbetter et al. sized the battery system by varying energy storage capacity, inverter size (power capability), and a grid demand limit, specific to a selection of residences in Canada. By limiting the failure (i.e., grid demand exceeding the demand limit) count to zero, authors suggested typical system sizes ranged from $5 \mathrm{kWh}(2.6 \mathrm{~kW})$ for low electricity consumption homes to $22 \mathrm{kWh}$ $(5.2 \mathrm{~kW})$ for homes with electric space heating [24]. For industrial users, Oudalov and Cherkaoui utilized dynamic programming to optimize the dispatch strategy of storage with a set of inputs including demand profiles, storage (dis-)charge, battery parameters, and the value of the shaved power [25]. The optimization objective was to maximize the electricity bill reduction while accounting for battery system cost. Their results showed that for an industrial consumer with a maximum peak demand of $\sim 1000 \mathrm{~kW}$, the annual electricity bill was reduced by $4 \%$ (demand charge portion of bill by $8 \%$ ) compared to a baseline without a battery storage system. Finally, beyond the DR tariffs used in these studies, other incentives for consumers include arbitrage savings from real time (e.g., [26]) or day-ahead markets (e.g., [27]), and payments from ancillary markets (e.g., [4, 28]).

However, few studies provide detailed comparisons among the multitude of existing storage technologies (batteries, compressed, air, magnetic, etc.) and their different operating constraints (lifetime, maximum (dis-)charge rates, (dis-)charge losses, and healthy depth of discharge) and costs, although these affect the economic viability of storage-based DR schemes [21]. In this study, we determine the possible profit of a residential, storage-based peak shaving DR system for an average U.S. household under a currently available demand tariff (Con Edison) and across a range of different storage technologies (conventional and advanced batteries, flywheel, magnetic storage, pumped hydro, compressed air, and capacitors). Profit herein is defined as the tariff charge (i.e., electricity bill) reduction minus $L S C$ over the lifetime of the storage system. The lifetime (and thus $L S C$ ) is modeled as varying with the particular dispatch strategy and storage operating constraints, based on a total-energy-throughput approach. The impact of uncertainties in storage parameters such as costs, round-trip efficiencies, etc. is illustrated via several sensitivity tests. The present study differs from the previous loadshifting study in a range of aspects as discussed above. Moreover, for peak shaving DR applications specifically, to the best of our knowledge, the present study is the first to apply an agent-based model and a total-energy-throughput lifetime model to evaluate real tariffs and commercially available storage technologies.

\section{Data and methods}

To assess the sizing, dispatch strategy, and profit of a storage system for peak shaving for an average U.S. household, a DR scheme similar to that proposed by Zheng et al. $[14,21]$ is used as a basic configuration 
Zheng et al. - APEN-D-14-05563R1 - Manuscript (no changes marked) - Page $\mathbf{5}$ of 23

(Fig. 1). The control unit's dispatch strategy aims to maximize profit - defined as tariff charge (i.e., electricity bill) reduction minus $L S C$ over the storage lifetime - while accounting for storage operating constraints.

We first introduce the specific TOU demand tariff used in this work (section 2.1). We then explain the agent-based, appliance-level demand model (section 2.2). Section 2.3 characterizes the dispatch strategy and the role of the demand limit $(D L)$. We then describe the framework for $L S C$ and the total annual cost to the household (TAC) (section 2.4), followed by the storage lifetime model (section 2.5). Finally, section 2.6 describes the simulation-based approach to maximize profit by optimizing storage capacity and $D L$.
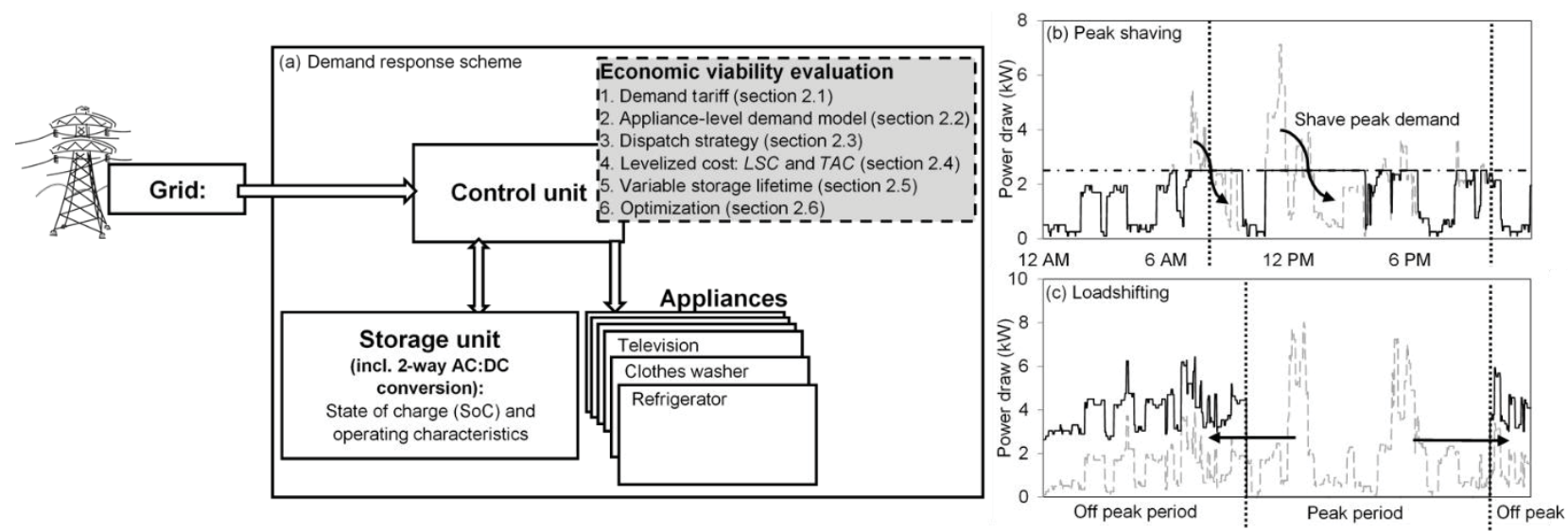

Fig.1. (a) Storage-based demand response (DR) scheme (open arrows indicate electricity flows): In charging mode, the control unit diverts electricity to the storage. In discharging mode, the control unit supplies appliances with electricity from storage and, when required, from the grid as well. (b) Illustrates the basic mechanism of peak shaving. Arrows indicate where peaks in appliance demand, regardless of when they occur, are smoothed by supplementing grid electricity with stored electricity. Storage is re-charged whenever appliance demand is lower than a preset demand limit $(D L)$. Long-dashed line reflects a specific $D L$ for a particular storage technology and season (section 2.3). (c) Illustrates basic loadshifting (for comparison only): Electricity usage is shifted from peak to off peak periods. Dashed grey line indicates appliance demand load while solid black line shows the actual load passed on to the grid (from storage and appliances combined).

\subsection{Demand tariff}

Demand tariffs for residential consumers are available from Con Edison (Service classification (SC) No.8; Page 435 - 447 in [29]): Consumers are charged according to their highest power demand at any point during a one month billing period (demand charge, charged in $\$$ per $\mathrm{kW}$, where $\mathrm{kW}$ are 30 min averages, determined by specific metering equipment by Con Edison as actual $\mathrm{kWh}$ consumed over $30 \mathrm{~min}$ intervals). Note that demand tariffs also have a separate, additional charge for energy, charged in $\$$ per $\mathrm{kWh}$ which amount to $\sim 25 \%$ of the total tariff charge for an average U.S. household (Fig. 6). We base our peak shaving application on one specific TOU demand tariff (SC8, Rate III; henceforth "TOU tariff" unless stated otherwise). For summer months, the demand charge is assessed each month based on the maximum load that occurs during three time periods (three peaks): (i) Monday to Friday, 8 am-6 pm; (ii) Monday to Friday, 8 am-10 pm; (iii) all hours of all days. For the remaining months of the year, the tariff records only two peaks: Monday to Friday, 8 am-10 pm and all hours of all days. Different peaks are assessed at different charge rates, and the monthly demand charge is the summation of these three (two) demand charges. The energy charge portion charges different rates per kWh for peak periods (Monday to 
Zheng et al. - APEN-D-14-05563R1 - Manuscript (no changes marked) - Page $\mathbf{6}$ of 23

Friday, 10 am-10 pm) and off-peak periods (all other hours). Both energy charge rates and demand charge rates further differ between summer months (June to September) and other months. Finally, there are fixed monthly charges for metering services. Charge rates used in our model are based on 2012 prices with details given in Supplementary Data (SD).

\subsection{Appliance-level demand model}

Residential demand profiles used in this work are simulated by an agent-based, appliance-level demand model in the time domain [30-34], details of which are described in [21]. Briefly, the model aggregates stochastically generated individual appliance demand profiles to generate an aggregate household demand profile at one minute resolution. The appliance demand profiles are calibrated to switch-on probabilities based on surveys (American Time Use Survey [35]). The model was shown to faithfully reproduce electricity consumption features of an average U.S. household, on both the individual appliance level and the aggregate household level, and including systematic variations across seasons due to air conditioning and electric space heating [21]. The simulated household consumes $31 \mathrm{kWh}$ electricity per day (average across seasons), with an average monthly peak demand of $6.5 \mathrm{~kW}$ (averaged on 30 minutes) for summer months and $5.7 \mathrm{~kW}$ for the remaining months.

\subsection{Dispatch strategy}

We first define a target $D L$ on the grid. $D L$ is either set constant throughout the year (constant $D L$ ) or set to three different values, one for summer, one for winter, and one for spring/fall (seasonal DLs; Results). Whenever the aggregate demand from appliances is above the set limit, the control unit discharges the storage to meet the incremental demand beyond the $D L$. For example, with storage being discharged (Fig. 2b), the demand on the grid is reduced from $\sim 9.2 \mathrm{~kW}$ (e.g., Point A in Fig. 2a) to $2.5 \mathrm{~kW}$ (e.g., Point B in Fig. 2d). In contrast, if the aggregate appliances demand is below $D L$, storage (if not already full) is charged at the dynamically calculated charge rate. This charge rate is calculated such that the total power draw from the grid for appliances, storage charging, and power conversion losses combined will not exceed $D L$. Furthermore, to prevent early degradation of the storage equipment (details, see section 2.5), storage is never discharged beyond the healthy depth of discharge $\eta_{\mathrm{DoD}}$ and never (dis-)charged above its maximum (dis-)charge power $P_{\max }$ (Eq. 1), as shown in Fig. $2 \mathrm{~b}$ and c. $\eta_{\mathrm{DoD}}$ and $P_{\max }$, which vary by storage technology, were inferred from various vendor data and literature (same as in [21]).

Note that on occasion, the power demand passed on to the grid may indeed exceed $D L$ (e.g., Point D in Fig.2d), namely when the appliance demand minus $P_{\max }$ surpasses $D L$ (or when storage is empty, i.e., state of charge $(S o C)$ at $\left(1-\eta_{\text {DoD }}\right)$; e.g., Point $\mathrm{C}$ in Fig. $\left.2 \mathrm{c}\right)$. As such, $D L$ must be interpreted as a demand target, rather than a hard limit. This leads to lower $T A C$, by essentially trading off lower $L S C$ against higher occasional demand charges, an effect that will be addressed as part of finding optimum storage capacity and $D L$ (Results). 

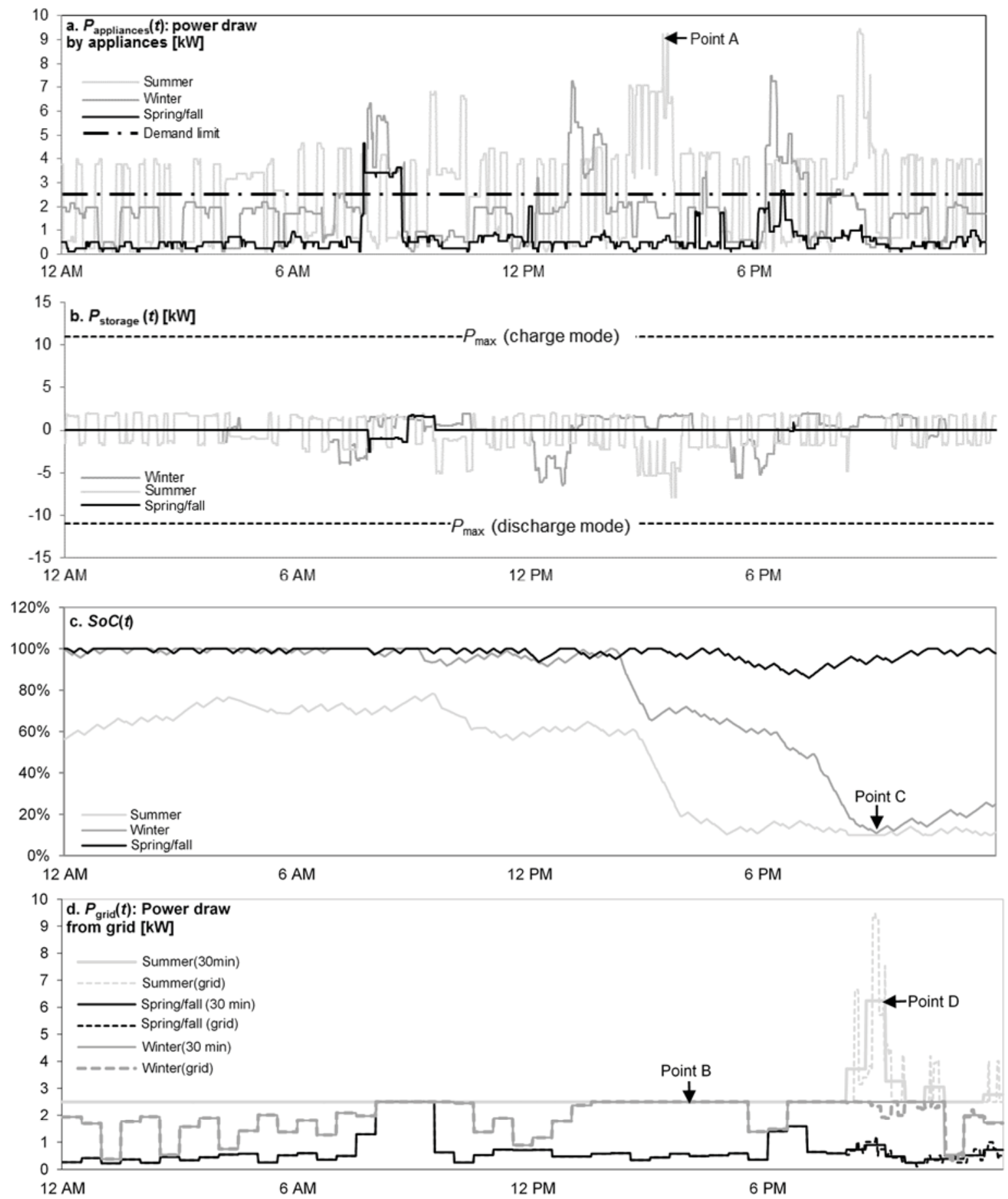

Fig. 2. Illustration of storage dispatch strategy via three examples: One random day in summer (light grey), one in winter (dark grey) and one in spring/fall months (black), with $\mathrm{ZnMnO}_{2}$ batteries installed (10 kWh effective capacity, $90 \%$ healthy depth of discharge $\left(\eta_{\mathrm{DoD}}\right)$ and $2.5 \mathrm{~kW}$ demand limit $\left.(D L)\right)$. (a) Appliances demand simulated by the demand model. Dashed line indicates $D L$ of $2.5 \mathrm{~kW}$ for all three days. (b) Storage dispatch: Dotted lines indicate the maximum (dis-)charge power $\left(P_{\max }\right)$. (c) State of charge $(S o C)$. (d) Power draw from the grid: Dotted lines show actual demands, from both appliances and storage (incl. charging and power conversion losses). Solid lines reflect the same demand, but filtered for a 30 minutes average which is the basis for the tariff. 
Charge mode : $P_{\text {grid }}(t)=\frac{P_{\text {storage }}(t)}{\eta_{\text {in }}}+P_{\text {appliance }}(t) \leq D L$

Discharge mode : $P_{\text {grid }}(t)=P_{\text {appliance }}(t)+P_{\text {storage }}(t) \times \eta_{\text {out }}$

$$
\begin{aligned}
& \operatorname{SoC}(t) \geq 1-\eta_{\mathrm{DoD}} \\
& \left|P_{\text {storage }}(t)\right| \leq P_{\max }
\end{aligned}
$$

Where $P_{\text {storage }}(t)$ denotes the storage (dis-)charge power (negative, if the storage is being discharged) at time step $t$, $P_{\text {apppliances }}(t)$ denotes the power draw required by appliances at time step $t$, SoC $(t)$ denotes storage state of charge at time step $t$, $\eta_{\text {DoD }}$ denotes the healthy depth of discharge of storage, $\eta_{\text {in }}$ denotes the ratio of electricity stored to electricity drawn from the grid by storage, $\eta_{\text {out }}$ denotes the efficiency of converting energy stored to electricity being supplied to appliances ( $\eta_{\text {in }}$ and $\eta_{\text {out }}$ are equal in value), $P_{\text {grid }}(t)$ denotes the power draw from the grid at time step $t$, $P_{\max }$ denotes the maximum (dis-)charge power (specified to storage technologies) as defined in [21].

\subsection{Levelized cost: LSC and TAC}

A variety of electricity storage technologies are applied in our analysis. $L S C$ follows the same methodology as described in $[14,21]$, however, with an additional sub-model that determines storage lifetime (section 2.5). LSC consists of constant annual payments (principal repayment and 10\% annualized interest) for the storage equipment (Eq. 2). This equipment cost is broken down into two parts: (i) A US\$ 2,000 fixed cost ([21], Discussion) reflects installation parts \& labor; (ii) a size-dependent cost (for the storage, power conversion, and control unit combined system) scales proportionally to the storage nominal capacity $(N C, \mathrm{kWh}) . N C$ is adjusted for efficiencies based on the electricity flow illustrated in Fig. 2 of [21]: The metric of effective capacity $(E C)$, which reflects the maximum amount of electricity stored that can be withdrawn and used by appliances after (dis-)charge and power conversion losses, is used throughout this paper (Eq. 3).

$$
\begin{aligned}
& L S C=\left(C_{\text {purchase }} \times N C+C_{\text {installation }}\right) \times \xi \\
& E C=N C \times \eta_{\text {out }} \times \eta_{\text {DoD }}
\end{aligned}
$$

Where $L S C$ denotes the levelized cost of storage equipment (annualized),

$C_{\text {purchase }}$ denotes the purchase cost of the storage, power conversion, and control unit combined system (excl. installation), per kWh nominal capacity,

$E C$ denotes the effective capacity of storage,

$N C$ denotes the nominal capacity of storage,

$C_{\text {installation }}$ denotes the installation cost (one-time parts and labor, excl. storage itself),

$\xi$ denotes the levelization multiplier (similar to a capital recovery factor) (Eq. 4).

Equipment costs, total available cycles, and other parameters (i.e., storage (dis-)charge efficiency, $\eta_{\text {DoD, }}$ and power conversion efficiency) obtained from vendors are used as in [21]. We use the geometric mean 
of lowest and highest purchase costs in the literature and arithmetic means for all other parameters in our study (discussed in [21]). Levelization multipliers are calculated as follows:

$$
\xi=\frac{r \times(1+r)^{k}}{(1+r)^{k}-1}
$$

Where $r$ denotes the interest rate,

$k$ denotes the storage lifetime (e.g., for a lifetime of 5.2 years, $k=5.2$ ).

Total annual cost (TAC per household, Eq. 5) equals the sum of $L S C$ and the annual tariff charge under the TOU tariff with peak shaving applied. The profit is defined as the difference between $T A C$ and the non-DR tariff charge under the same tariff (Eq. 6). Tariff charges (Eq. 7) are determined by combining the simulation-determined energy $(\mathrm{kWh})$ and demand $(\mathrm{kW})$ characteristics of the household with the respective tariff rates from Con Edison, as outlined in section 2.1 and tariff parameters as in $S D$.

$$
\begin{aligned}
& T A C=L S C+C_{\text {tariff, with DR }} \\
& P r=C_{\text {tariff, noDR }}-T A C
\end{aligned}
$$

Where $\operatorname{Pr}$ denotes the annual profit (tariff charge reduction from DR minus $L S C$ ),

$T A C$ denotes the total household annual cost,

$C_{\text {tariff, with DR }}$ denotes the annual tariff charge under the TOU tariff with DR,

$C_{\text {tariff, no DR }}$ denotes the annual tariff charge under the TOU tariff without DR.

$$
C_{\text {tariff }}=\sum_{i=1}^{12}\left[C_{\text {tariff, metering }}+\sum_{j=1}^{3}\left(U_{\text {energy }}^{i, j} \times C_{\text {tariff, energy }}^{i, j}+U_{\text {demand }}^{i, j} \times C_{\text {tariff, demand }}^{i, j}\right)\right]
$$

Where $C_{\text {tariff, metering }}$ denotes the monthly metering service charge [US\$],

$C^{i, j}$ tariff, energy denotes the energy charge rate during month $i$ in time period $j[\mathrm{US} \$ / \mathrm{kWh}$ ],

$C^{i, j}$ tariff, demand denotes the demand charge rate during month $i$ in time period $j[\mathrm{US} \$ / \mathrm{kW}$ ],

$U^{i, j}{ }_{\text {energy }}$ denotes the energy usage during month $i$ in time period $j[\mathrm{kWh}$,

$U^{i, j}$ demand denotes the 30-min average maximum demand during month $i$ in time period $j$ $[\mathrm{kW}]$.

\section{$2.5 \quad$ Variable storage lifetime}

In loadshifting applications, storage is typically charged and discharged once a day and to its full available capacity (i.e., $\eta_{\text {DoD }}$ ). Therefore, such work usually approximates the storage lifetime based on storage lifetime-available full cycles (e.g., 3650 cycles would correspond to 10-year lifetime [21]). In contrast, as illustrated in Fig.1, the peak shaving strategy in the present work typically charges and discharges the storage several times daily in order to shave multiple peaks per day while keeping required storage capacity low. Alternatively, one may use larger $E C$, but this would increase $L S C$ unless there were no interest payments and installation cost. Since peak magnitudes change stochastically and the storage $S o C$ varies throughout the day, each (dis-)charge event changes $S o C$ to varying degrees (between (1- $\left.\eta_{\text {DoD }}\right)$ and $100 \%$ ), not always to full cycles. This adds further complexities to determining the optimum $D L$ (i.e., the one resulting in lowest $T A C$ ) because for most storage technologies, lifetime (and thus $L S C$ ) depends on number and depth of each (dis-)charge cycles. This necessitates a more complex storage lifetime model that is not merely based on the number of cycles. 
Lifetime prediction models vary with different battery technologies [36-40]. Typically, two battery lifetime metrics are given by the manufacturers: cycling lifetime and calendar lifetime. Calendar aging is due to, for example, parasitic reactions that gradually consume active materials [41] or aging of nonactive components. These can occur whether the battery is actually in use or not. In contrast, cycling aging is more associated with degradation due to reactions of active materials with electrolytes during actual use [42].

To quantify the cycling lifetime of batteries, we use a total-energy-throughput model that assumes that a fixed amount of energy $(\mathrm{kWh})$ can be cycled through a battery before it requires replacement [43]. This method has been shown to closely approximate real storage lifetime at standard operating conditions, i.e., not exceeding $\eta_{\mathrm{DoD}}$ and $P_{\max }$ (and at standard temperature) [37]. For example, for a specific type of Lithium ion battery, Peterson et al. showed that the cumulative energy that could be cycled throughout the battery's life was statistically independent of the actual $S o C$ in each cycle (i.e., partial or full cycles) [44]. However, some other studies showed that the total energy that can be cycled may indeed vary as a function of $S o C$, temperature, and (dis-)charge rate (e.g., [45, 46]). Usually higher energy-throughput was achieved when batteries were cycled only at higher $S o C$, in other words avoiding full cycles (e.g., [47]). Therefore, to remain conservative (i.e., short lifetime and thus high $L S C$ ), we use the total-energythroughput (at standard operating conditions) that is calibrated to full battery cycles as specified by the storage vendors/literature (Eq. 8), even if many of the actual cycles were indeed partial rather than full cycles and therefore a disproportionally higher number of cycles may have been possible until replacement became necessary. The cycling lifetime is thus calculated by dividing the total-energythroughput by the simulated annual energy that is cycled through storage (Eq. 9). For storage technologies other than batteries, the same total-energy-throughput model is used. Parameter details for full cycle equivalent, $\eta_{\mathrm{DoD}}$, efficiencies, and total-energy-throughput per one $\mathrm{kWh} E C$ are provided in Table 1.

Actual lifetime ( $k$ in Eq. 4) of each storage technology follows a hybrid approach of above cycling lifetime and calendar lifetime (20 years, [21]), namely by setting $k$ to the smaller of the two measures.

$$
\begin{aligned}
& E T_{\text {tot }}=N C \times n \times \eta_{\text {DoD }}=\frac{E C \times n}{\eta_{\text {out }}} \\
& k=\min \left(\frac{E T_{\text {tot }}}{E T_{\text {sim }}}, 20\right)
\end{aligned}
$$

Where $E T_{\text {tot }}$ denotes the total-energy-throughput,

$E T_{\text {sim }}$ denotes the simulated annual energy-throughput,

$n$ denotes the number of lifetime available full cycles as specified by vendors, other parameters as above.

\subsection{Optimization through iterative simulation}

To optimize the system for maximum profit, we vary $E C$ and $D L$ separately and calculate each resulting $T A C$. EC is varied from zero to the average daily electricity consumption ( $20 \%$ stepwise increases). $D L$ is varied from zero to $5.7 \mathrm{~kW}(10 \%$ stepwise increases $)$. For the seasonal $D L$ s method, we determine $T A C$ for 3 separate $D L$ s for each $E C$ : Summer, winter, and spring/fall. Optimal results are then determined based on which $E C$ and $D L($ s) yield lowest $T A C$. 
Zheng et al. - APEN-D-14-05563R1 - Manuscript (no changes marked) - Page 11 of 23

The peak shaving simulation model was developed in Microsoft Visual Basic. Simulations of one-year demand profiles at one minute resolution, dispatch of storage, and the resulting $T A C$ take about 8 minutes on a computer with $2.5 \mathrm{GHz}$ Intel Core i5-2520M CPU and 4 GB RAM.

Table 1: Cycles, healthy depth of discharge, (dis-)charge efficiency, and total-energy-throughput of each storage technology ${ }^{\dagger}$

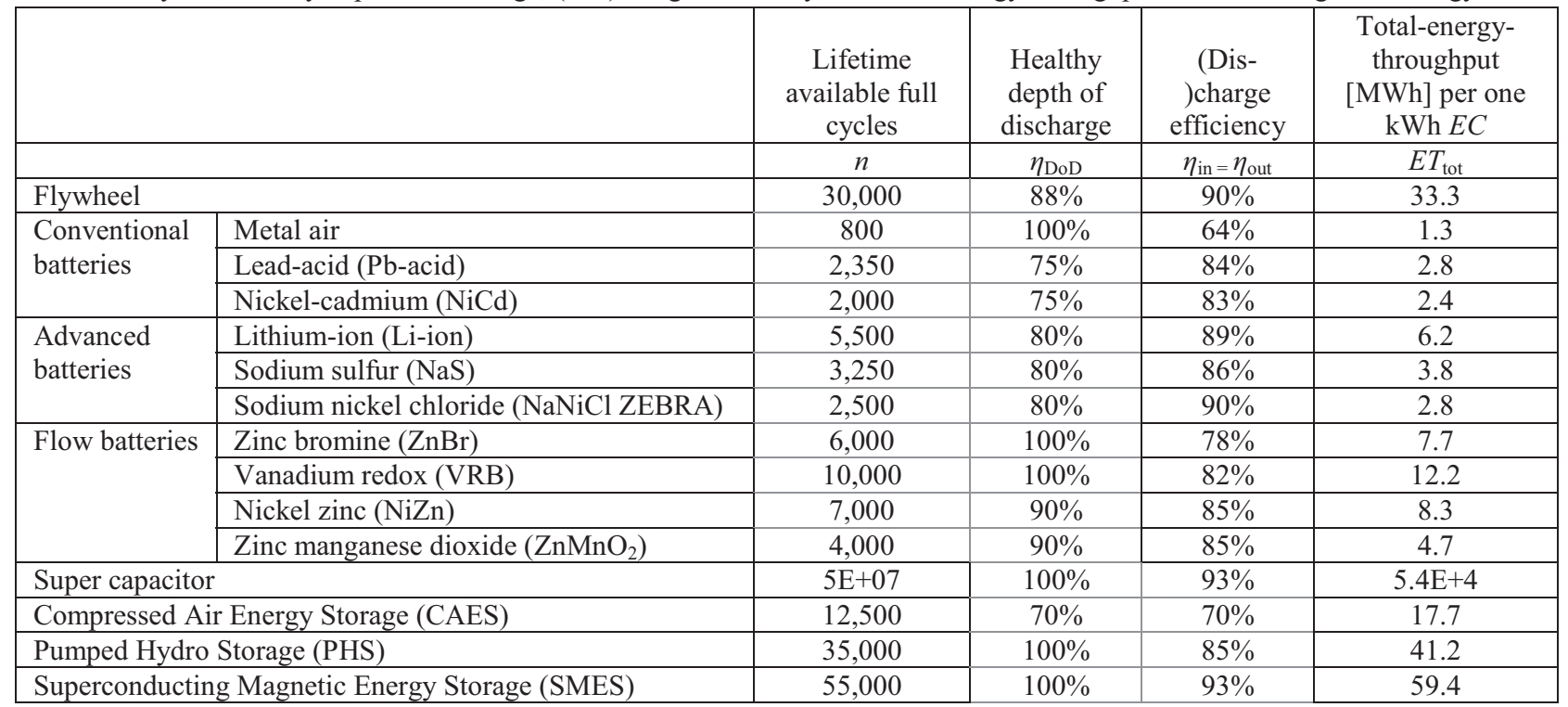

$\dagger$ Average of lowest and highest literature values [21]

\section{Results}

To analyze the various effects and tradeoffs that affect $T A C$, we first explore each effect in isolation: Section 3.1 shows how smaller $D L$ (to reduce demand charges) requires higher $E C$, and how this varies across seasons. In principle, installations with smaller $E C$ will lead to smaller $L S C$. However, smaller $E C$ will tend to increase the energy-throughput usage per day (as fraction of $N C$ ), therefore decreasing storage lifetime which in turn will increase or decrease $L S C$ depending on the interest rate and the installation cost (section 3.2). Therefore, in section 3.3 we analyze the combined effects of $D L$ and $E C$ on $T A C$. We then analyze the TAC breakdown in demand versus energy charge, including seasonal effects and LSC (section 3.4). Finally, accounting for all above effects simultaneously, and for each storage technology separately, we determine pairings of $E C$ and constant or seasonal $D L(\mathrm{~s})$ that provide lowest overall $T A C$ and thus maximum profit for the household (section 3.5).

\subsection{Impact of DL on EC}

To explore the interactions between $D L$ and $E C$ and their potential impact on $T A C$, Fig. 3 plots $E C$ that is required such that demand on the grid will never exceed $D L$. A $\mathrm{ZnMnO}_{2}$ battery system is used as an example to illustrate the impact. Fig. 3 shows that smaller $D L$ (to reduce the demand charge) requires at first moderately and then steeply increasing $E C$. For example, in summer months, to reduce the $D L$ from $4.7 \mathrm{~kW}$ to $3.5 \mathrm{~kW}(1.2 \mathrm{~kW}$ reduction) requires only $1.7 \mathrm{kWh}$ additional $E C$, while a $20 \mathrm{kWh} E C$ increment is needed to decrease $D L$ by a further $1.1 \mathrm{~kW}$ to $2.4 \mathrm{~kW}$. In this example, incremental peak reductions are nearly the same but additional $E C$ and thus $L S C$ increase twelve-fold. This suggests the diminishing economic incentive for decreasing $T A C$ as $D L$ decreases and $E C$ increases. 
For same $D L$, required $E C$ varies by season. In winter, a $D L$ of $2 \mathrm{~kW}$ would require more than twice the $E C$ as that required in spring/fall months. In summer, with air conditioning raising monthly electricity usage and monthly peak demand, households would require more electricity storage to reduce peaks to the same $D L$ as in other months. However, storage equipment typically lasts significantly longer than 1 or 2 seasons. This makes adjusting $E C$ across seasons un-economical. However, despite constant $E C$ across seasons, $D L$ and thus the demand charge in non-summer months could be reduced compared to summer months, thus lowering year round $T A C$. In a variation of the dispatch strategy, we thus allow $D L$ to assume different values for different seasons (seasonal $D L \mathrm{~s}$ ).

Finally, we recognize that an $E C$ large enough to ensure that demand on the grid will never exceed $D L$ may in fact not be the optimal strategy with respect to lowest $T A C$. Instead, smaller $E C$ may be costoptimal, because the associated smaller $L S C$ may more than offset the increased tariff charge from occasional breaches of the $D L$ (i.e., demand on grid is occasionally higher than $D L$ target). Therefore, in sections 3.3-3.5, EC is not set as a function of $D L$, but rather set to whichever value yields lowest $T A C$.

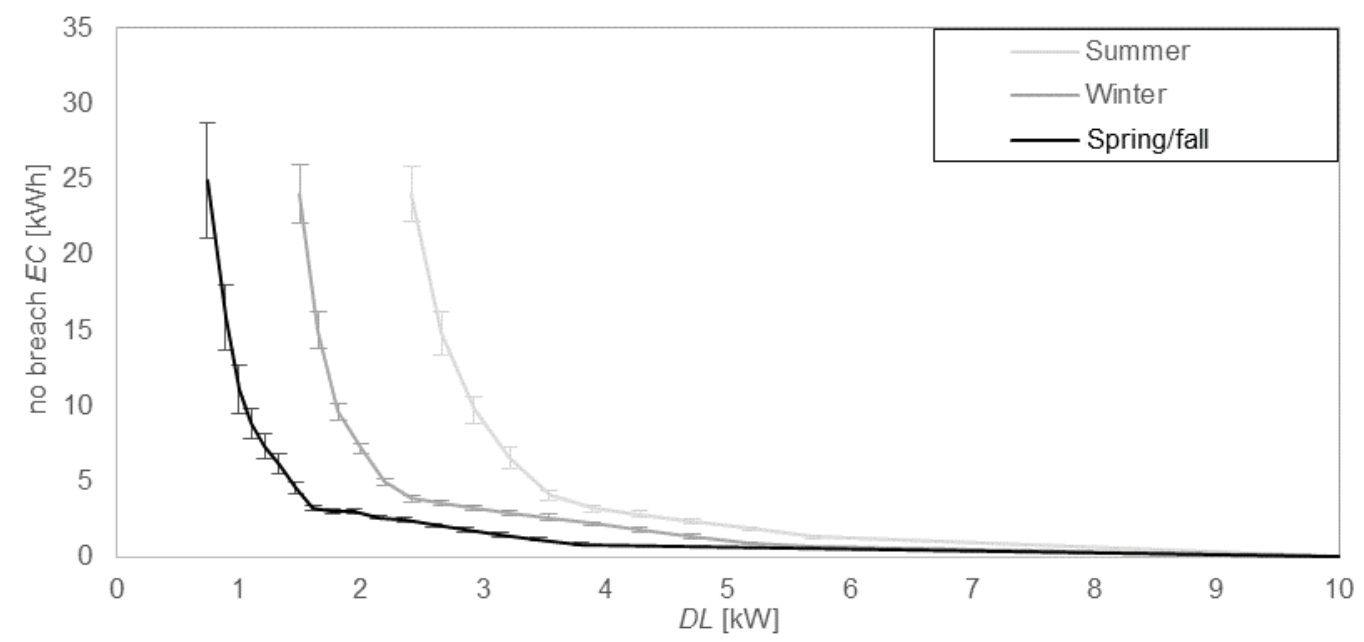

Fig. 3. Relationship between demand limit $(D L)$ and effective capacity $(E C)$ required such that grid demand never exceeds $D L$ (example of $\mathrm{ZnMnO}_{2}$ battery). Error bars indicate standard error of the mean from the stochastic simulations.

\subsection{Impact of DL and EC on storage lifetime}

Fig. 4 shows the impact of $E C$ and $D L$ on storage lifetime, thus also impacting $L S C$ and in turn $T A C$ (example of $\mathrm{ZnMnO}_{2}$ battery). The simulated lifetime generally decreases with decreasing $E C$ and decreasing $D L$. With smaller $E C$, the total-energy-throughput is smaller (Eq. 8), resulting in a shorter cycling lifetime. This may increase or decrease $L S C$, depending on the interest rate and the installation cost. More importantly however, with smaller $D L$, appliance demand will exceed $D L$ more frequently. In turn, the dispatch strategy in the simulation will (dis-)charge storage more frequently and to a larger depth, thus further shortening the storage lifetime. For any given $E C$, aiming for small $L S C$ will thus favor high $D L$. But, small $E C$ and high $D L$ will generally lead to more frequent, high demands on the grid, thus increasing the tariff charge and $T A C$. This tradeoff will be optimized in the analyses in the following sections. 


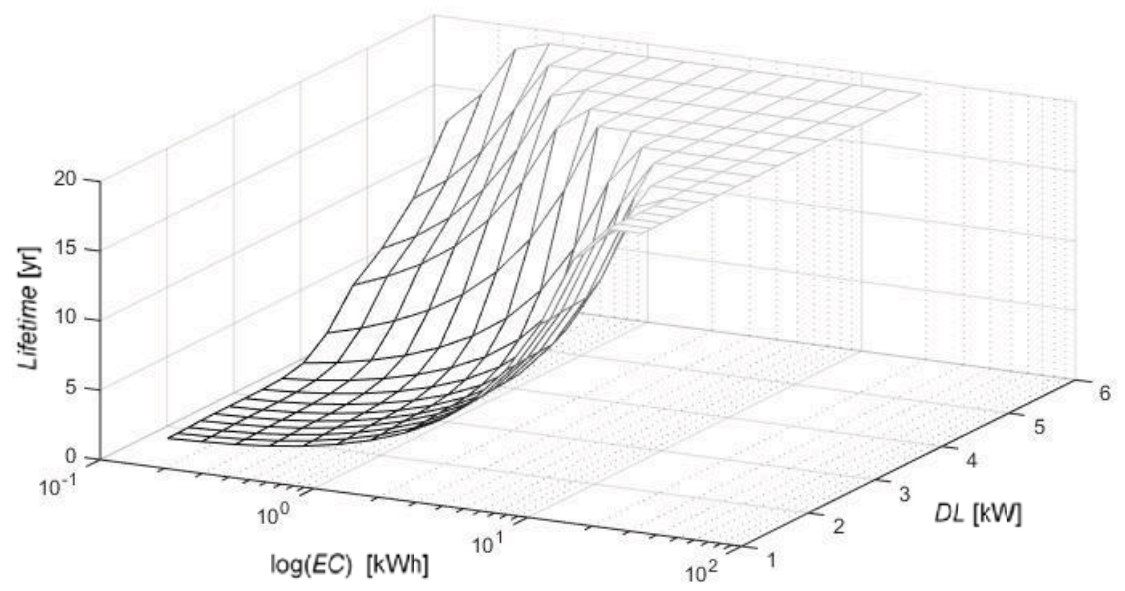

Fig. 4. Storage lifetime as a function of effective capacity $(E C)$ and demand limit $(D L)$ (example of $\mathrm{ZnMnO}_{2}$ battery). Lifetime is capped at the calendar lifetime of the hardware (20 years, Eq. 9).

\subsection{Combined effects of non-seasonal DL and EC on TAC}

Fig. 5 shows the above trade-offs and their impact on $T A C$ quantitatively (example of $\mathrm{ZnMnO}_{2}$ battery). With decreasing $D L, T A C$ at first decreases due to lower tariff charge but then increases due to larger $L S C$. Likewise, with decreasing $E C, T A C$ first decreases due to lower $L S C$ but then increases due to higher tariff charge (more frequent and higher peak demands passed on to the grid). Optimal $E C$ and $D L$ are identified by the lowest point $(E C=12.7 \mathrm{kWh}, D L=2.9 \mathrm{~kW}$ for the example in Fig. 5).

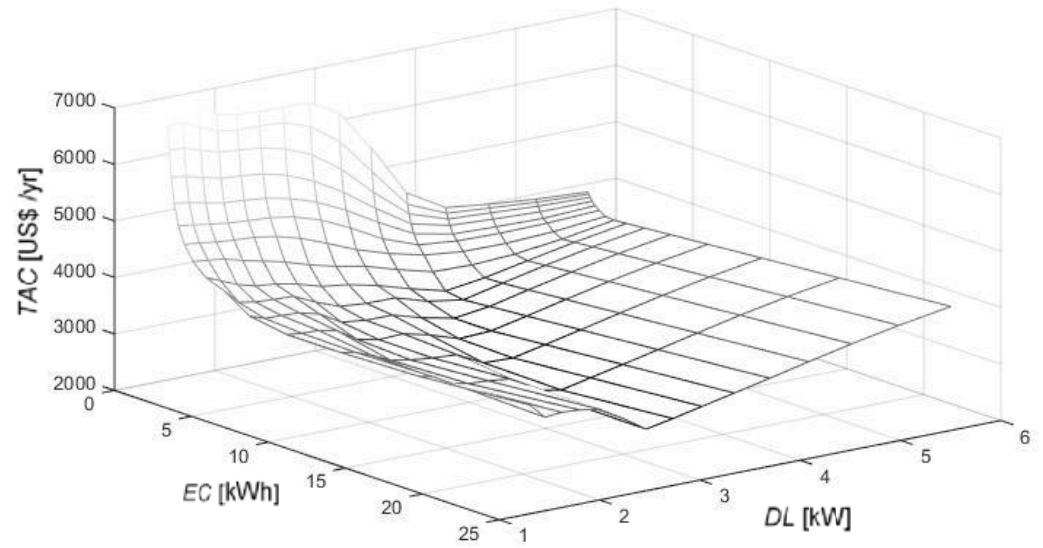

Fig. 5. Total household annual cost $(T A C)$ as a function of effective capacity $(E C)$ and demand limit $(D L)$ (example of $\mathrm{ZnMnO}_{2}$ battery). TAC includes levelized storage cost (LSC) and annual tariff charge.

\subsection{TAC breakdowns}

We investigated the composition of the tariff charge and associated seasonal effects by breaking down $T A C$ into eight parts (example of $\mathrm{ZnMnO}_{2}$ battery). The eight parts are: 1) Demand charge in summer; 2) energy charge in summer; 3) demand charge in winter; 4) energy charge in winter; 5) demand charge in the remaining months (i.e., in spring/fall months); 6) energy charge in the remaining months; 7) metering service charge; 8) LSC. 
The second and third columns in Fig. 6 show the source of profit by utilizing the proposed dispatch strategy using either constant or seasonal $D L(\mathrm{~s})$. Using DR, although it moderately increases the energy charges by US $\$ 43$, constant $D L$ results in a US\$ 650 reduction in the demand charge in summer months. The reduction for both winter and spring/fall months is $\sim$ US $\$ 350$. The reductions are partly offset by the $L S C$ of $\sim$ US $\$ 510$ per year for this specific example, resulting in a $\sim$ US $\$ 790$ profit. By applying different $D L$ s for different seasons, the strategy reduces $T A C$ by further US $\$ 300$ beyond that with constant $D L$. $\sim$ US\$ 250 of this reduction stems from the demand charge in spring/fall months. The summer demand charge increases by US\$ 30 , while the winter demand charge decreases by US\$ 75 . The smaller optimal $E C$ further decreases $L S C$ by US\$ 13. Finally, the metering service charge of US\$ 142 is the same for in all three columns.

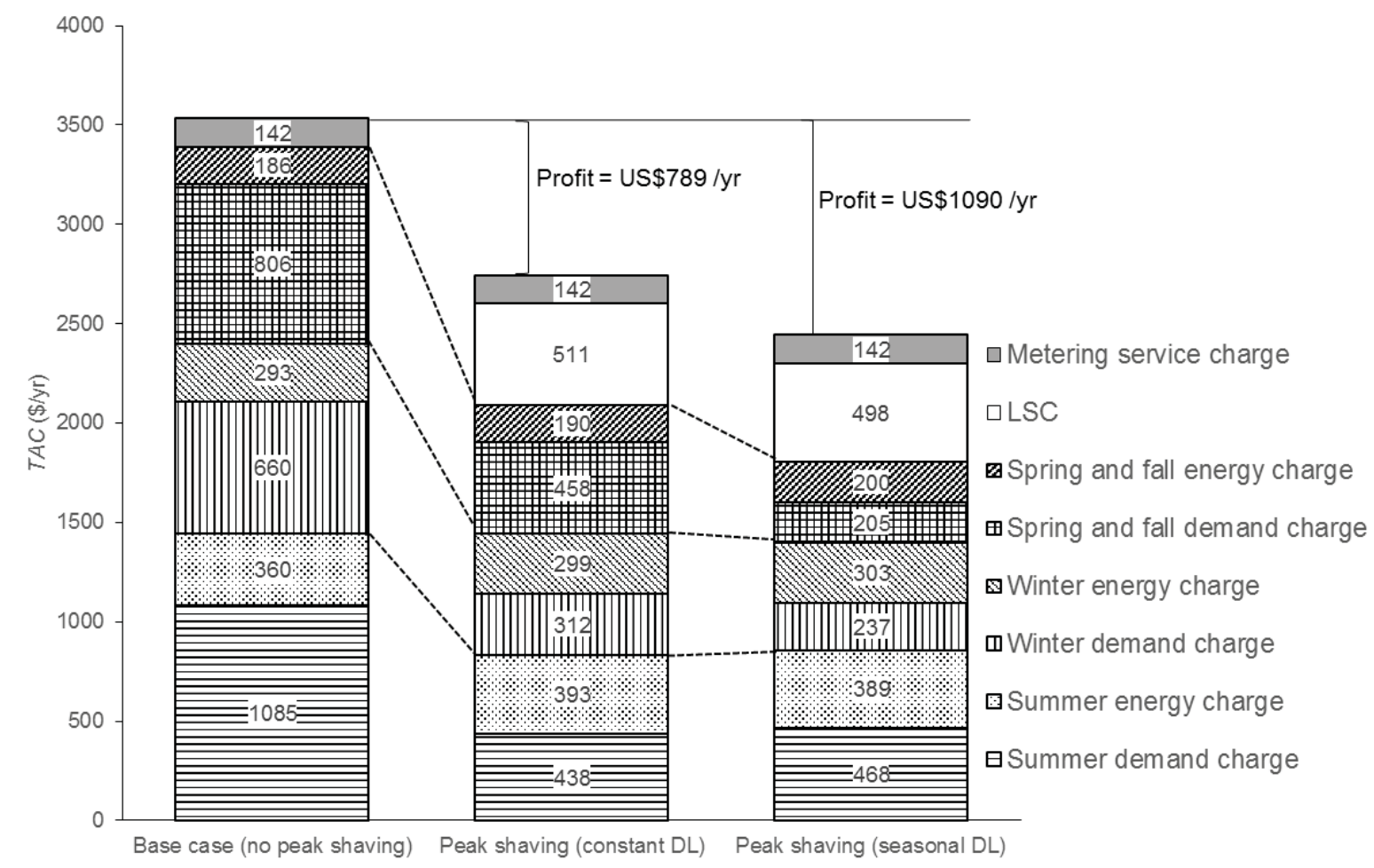

Fig. 6. Breakdown of total household annual cost (TAC; example of $\mathrm{ZnMnO}_{2}$ battery). First column shows non-demand response (DR) annual tariff charge. Second column shows $T A C$ under constant demand limit $(D L)$, with $12.7 \mathrm{kWh}$ effective capacity $(E C)$ battery installed and $2.9 \mathrm{~kW} D L$. The last column shows $T A C$ under seasonal $D L \mathrm{~s}$, with $12.1 \mathrm{kWh} E C$ battery installed, $3.0 \mathrm{~kW}$ summer $D L, 2.2 \mathrm{~kW}$ winter $D L$, and $1.3 \mathrm{~kW}$ spring/fall $D L$. Profit is defined as the difference between $T A C$ with peak shaving (inclusive of the levelized storage cost $(L S C)$ ) and the charge under the same tariff, however without storage and peak shaving.

\subsection{Optimization and economic viability}

Table 2 summarizes maximum annual profit for all storage technologies and constant versus seasonal $D L(\mathrm{~s})$, using base case parameters as well as conservative parameters (Discussion). Base case profits range from as low as US $\$ 51$ for nickel cadmium battery (1\% of the non-DR annual tariff charge) to US\$ 1,376 for pumped hydro storage (PHS) (39\%). All investigated storage technologies are economically viable when using seasonal $D L$ s except for flywheel and superconducting magnetic energy storage (SMES). The annual loss is US\$ 37 and US\$ 216 for flywheel and SMES, respectively. Storage 
technologies with high purchase cost per $E C$, i.e., NiCd and lithium-ion (Li-ion) batteries (also used in household-connected electric vehicles [48]), flywheel, and SMES, are not economically viable with constant $D L$. Storage lifetimes range from 11 to 20 years. Flow batteries last 20 years as shown in Table 2. Due to their smaller total-energy-throughputs, metal air, lead-acid (Pb-acid), NiCd, sodium sulfur (NaS), and sodium nickel chloride (ZEBRA) batteries have lifetimes of less than 20 years in both methods. Nonbattery storage technologies all last 20 years (lifetimes capped at 20 years to account for non-use dependent aging of the equipment).

Table 2: Optimized total household annual cost (TAC), profit, and storage lifetime, under either constant or seasonal $D L(\mathrm{~s})$. Negative profits indicate that the storage technology is not economically viable $\dagger$

\begin{tabular}{|c|c|c|c|c|c|c|c|c|c|}
\hline & & \multicolumn{2}{|c|}{$\begin{array}{c}\text { Base case } \\
T A C(\mathrm{US} \$ / \mathrm{yr})\end{array}$} & \multicolumn{2}{|c|}{$\begin{array}{c}\text { Base case } \\
\text { Profit (US\$ /yr) }\end{array}$} & \multicolumn{2}{|c|}{$\begin{array}{c}\text { Base case } \\
\text { Lifetime (yr) }\end{array}$} & \multicolumn{2}{|c|}{$\begin{array}{c}\text { Sensitivity test } \\
\text { (conservative } \\
\text { parameters } \dagger \dagger ; \\
\text { seasonal } D L s \text { ) }\end{array}$} \\
\hline & & $\begin{array}{l}\text { Constant } \\
D L\end{array}$ & $\begin{array}{l}\text { Seasonal } \\
D L \mathrm{~s}\end{array}$ & $\begin{array}{l}\text { Constant } \\
D L\end{array}$ & $\begin{array}{l}\text { Seasonal } \\
D L \mathrm{~s}\end{array}$ & $\begin{array}{l}\text { Constant } \\
D L\end{array}$ & $\begin{array}{l}\text { Seasonal } \\
D L \mathrm{~s}\end{array}$ & $\begin{array}{l}T A C \\
(\mathrm{US} \$ / \mathrm{yr})\end{array}$ & $\begin{array}{l}\text { Profit } \\
\text { (US\$ /yr) }\end{array}$ \\
\hline Flywheel & & 3,836 & 3,579 & -294 & -37 & 20 & 20 & 3,946 & -404 \\
\hline \multirow{3}{*}{$\begin{array}{l}\text { Con- } \\
\text { ventional } \\
\text { batteries }\end{array}$} & Metal air & 3,016 & 2,714 & 526 & 828 & 12 & 13 & 3,308 & 234 \\
\hline & Pb-acid & 3,276 & 3,051 & 266 & 491 & 17 & 11 & 3,952 & -410 \\
\hline & NiCd & 3,618 & 3,491 & -76 & 51 & 16 & 14 & 3,876 & -334 \\
\hline \multirow{3}{*}{$\begin{array}{l}\text { Advanced } \\
\text { batteries }\end{array}$} & Li-ion & 3,572 & 3,242 & -30 & 300 & 20 & 20 & 3,973 & -431 \\
\hline & $\mathrm{NaS}$ & 3,371 & 3,130 & 171 & 412 & 19 & 15 & 3,923 & -381 \\
\hline & ZEBRA & 2,783 & 2,509 & 759 & 1,033 & 19 & 15 & 2,641 & 901 \\
\hline \multirow{4}{*}{$\begin{array}{l}\text { Flow } \\
\text { batteries }\end{array}$} & $\mathrm{ZnBr}$ & 3,194 & 2,805 & 348 & 737 & 20 & 20 & 3,576 & -34 \\
\hline & VRB & 3,085 & 2,694 & 457 & 848 & 20 & 20 & 3,202 & 340 \\
\hline & NiZn & 3,242 & 2,853 & 300 & 689 & 20 & 20 & 2,860 & 682 \\
\hline & $\mathrm{ZnMnO}_{2}$ & 2,784 & 2,445 & 758 & 1,097 & 20 & 20 & 2,555 & 987 \\
\hline \multicolumn{2}{|c|}{ Super capacitor } & 3,124 & 2,740 & 418 & 802 & 20 & 20 & 2,892 & 650 \\
\hline \multicolumn{2}{|c|}{ Compressed air (CAES) } & 2,746 & 2,430 & 796 & 1,112 & 20 & 20 & 3,099 & 443 \\
\hline \multicolumn{2}{|c|}{ PHS } & 2,435 & 2,166 & 1,107 & 1,376 & 20 & 20 & 2,402 & 1,140 \\
\hline \multicolumn{2}{|l|}{ SMES } & 3,885 & 3,758 & -343 & -216 & 20 & 20 & 3,981 & -439 \\
\hline
\end{tabular}

$\uparrow$ Standard errors of the means due to the stochastic simulations range from US\$ 5 to 25 for TAC.

$\uparrow \nmid$ Conservative parameters use highest cost and lowest efficiencies in the literature (same as in [21]).

Table 3: Optimal effective capacity $(E C)$ and optimal constant or seasonal $D L(\mathrm{~s}) \dagger$

\begin{tabular}{|c|c|c|c|c|c|c|c|}
\hline & & \multicolumn{2}{|c|}{ Constant $D L$ throughout the year } & \multicolumn{4}{|c|}{ Seasonal $D L s$} \\
\hline & & $E C(\mathrm{kWh})$ & $D L(\mathrm{~kW})$ & $E C(\mathrm{kWh})$ & $\begin{array}{c}\text { Summer } D L \\
(\mathrm{~kW})\end{array}$ & $\begin{array}{c}\text { Winter } D L \\
(\mathrm{~kW})\end{array}$ & $\begin{array}{c}\text { Spring/fall } D L \\
(\mathrm{~kW})\end{array}$ \\
\hline Flywheel & & 1.5 & 4.0 & 3.1 & 4.0 & 2.9 & 1.9 \\
\hline \multirow{3}{*}{$\begin{array}{l}\text { Conventional } \\
\text { batteries }\end{array}$} & Metal air & 30.8 & 3.1 & 28.5 & 3.9 & 2.2 & 1.5 \\
\hline & Pb-acid & 4.0 & 3.9 & 3.8 & 4.3 & 3.1 & 2.0 \\
\hline & NiCd & 2.8 & 4.3 & 2.5 & 5.1 & 4.0 & 3.0 \\
\hline \multirow{3}{*}{$\begin{array}{l}\text { Advanced } \\
\text { batteries }\end{array}$} & Li-ion & 2.9 & 3.8 & 3.2 & 4.1 & 3.0 & 1.9 \\
\hline & $\mathrm{NaS}$ & 3.2 & 3.9 & 3.6 & 4.3 & 3.1 & 2.0 \\
\hline & ZEBRA & 14.4 & 2.8 & 13.4 & 2.9 & 2.2 & 1.3 \\
\hline \multirow[t]{4}{*}{ Flow batteries } & $\mathrm{ZnBr}$ & 3.5 & 3.9 & 3.8 & 3.9 & 2.9 & 1.9 \\
\hline & VRB & 4.4 & 3.7 & 4.0 & 3.9 & 2.8 & 1.9 \\
\hline & NiZn & 3.2 & 3.8 & 3.8 & 3.9 & 2.8 & 1.9 \\
\hline & $\mathrm{ZnMnO}_{2}$ & 12.7 & 2.9 & 12.1 & 3.0 & 2.2 & 1.3 \\
\hline \multicolumn{2}{|l|}{ Super capacitor } & 3.6 & 3.7 & 4.0 & 3.7 & 2.7 & 1.7 \\
\hline \multicolumn{2}{|l|}{ CAES } & 18.4 & 3.0 & 12.5 & 3.2 & 2.4 & 1.4 \\
\hline \multicolumn{2}{|l|}{ PHS } & 26.8 & 2.6 & 25.0 & 2.7 & 1.9 & 1.2 \\
\hline \multicolumn{2}{|l|}{ SMES } & 0.4 & 4.1 & 1.9 & 4.7 & 3.9 & 2.8 \\
\hline
\end{tabular}

$\uparrow$ Standard errors of the means due to the stochastic simulations range from 0.02 to $2.4 \mathrm{kWh}$ for optimal ECs, from 0.1 to $0.3 \mathrm{~kW}$ for optimal $D L s$. 
Zheng et al. - APEN-D-14-05563R1 - Manuscript (no changes marked) - Page 16 of 23

Table 3 summarizes the optimal $E C$ s and $D L$ s for all studied storage technologies. Optimal $E C$ s span a wide range depending on the storage technology: $0.4 \mathrm{kWh}-30.8 \mathrm{kWh}$ for constant $D L$ and $1.9 \mathrm{kWh}-$ $28.5 \mathrm{kWh}$ for seasonal $D L \mathrm{~s}$. Optimal $D L \mathrm{~s}$ range from $2.6 \mathrm{~kW}$ to $4.3 \mathrm{~kW}$ for constant $D L$. By lowering the $D L \mathrm{~s}$ in non-summer months, seasonal $D L$ s yields higher profit than constant $D L$.

\section{Discussion}

\subsection{Demand tariffs versus energy tariffs}

For residential consumers, Con Edison offers both energy tariffs (SC 1; Page 387-389 in [29]) and demand tariffs. Energy tariffs charge households only according to their kWh drawn from the grid while demand tariffs combine charges for a household's energy $(\mathrm{kWh})$ and demand $(\mathrm{kW})$. Arbitrage savings by storage-enabled DR can be achieved under both tariffs: Consumers shift electricity consumption from peak hours to off peak hours (loadshifting under energy tariffs; [21]) or smoothen peak demands (peak shaving under demand tariffs; present study). But which of the two tariffs allow for higher profits?

Table 4 shows comparisons between achievable profits with storage-based DR under these two tariffs (using the same appliance demand model and same storage parameters such as purchase cost, $\eta_{\text {DoD, }}, P_{\max }$, etc.). Note that there is no monthly metering service charge (Fig. 6; $S D$ ) under the energy tariff but instead a monthly basic service charge of US \$24.30 per month [21]. However, the monthly charges for both tariffs are insignificant in comparison to the actual usage charges. For peak shaving (seasonal $D L s$ ), the highest annual profit is US\$ 1,376 , or $39 \%$ of the non-DR annual tariff charge under the same tariff (using PHS technology). For loadshifting, the highest profit is previously found to be US\$ 883 , or $28 \%$ of the non-DR tariff charge under the basic TOU energy tariff (using PHS technology). We find that lower $T A C$ and smaller optimum storage size are achieved by implementing the peak shaving strategy for all storage technologies except for CAES and PHS. As shown in Table 4, the peak shaving strategy (seasonal $D L s$ ) renders more storage technologies economically viable (defined as reduced tariff charge higher than LSC). Only $\mathrm{ZnMnO}_{2}$ battery, CAES, and PHS are economically viable under both tariffs.

Table 4: Economic comparison between the peak shaving strategy under the demand tariff (seasonal $D L s$ ) and the loadshifting strategy under the energy tariff ([21])

\begin{tabular}{|c|c|c|c|c|c|c|c|}
\hline & & \multicolumn{2}{|c|}{ Minimum $T A C$ (US\$ /yr) } & \multicolumn{2}{|c|}{ Optimal $E C(\mathrm{kWh})$} & \multicolumn{2}{|c|}{ Economically viable } \\
\hline & & Energy tariff & Demand tariff & Energy tarifft & Demand tariff & Energy tariff & Demand tariff \\
\hline Flywheel & & 3,847 & 3,579 & - & 3.1 & No & No \\
\hline \multirow{3}{*}{$\begin{array}{l}\text { Conventional } \\
\text { batteries }\end{array}$} & Metal air & 3,121 & 2,714 & 29.6 & 28.5 & No & Yes \\
\hline & Pb-acid & 3,590 & 3,051 & - & 3.8 & No & Yes \\
\hline & NiCd & 3,805 & 3,491 & - & 2.5 & No & Yes \\
\hline \multirow{3}{*}{$\begin{array}{l}\text { Advanced } \\
\text { batteries }\end{array}$} & Li-ion & 3,729 & 3,242 & - & 3.2 & No & Yes \\
\hline & $\mathrm{NaS}$ & 3,707 & 3,130 & - & 3.6 & No & Yes \\
\hline & ZEBRA & 2,704 & 2,509 & 27.9 & 13.4 & No & Yes \\
\hline \multirow{4}{*}{$\begin{array}{l}\text { Flow } \\
\text { batteries }\end{array}$} & $\mathrm{ZnBr}$ & 3,476 & 2,805 & - & 3.8 & No & Yes \\
\hline & VRB & 3,261 & 2,694 & 10.4 & 4.0 & No & Yes \\
\hline & NiZn & 3,513 & 2,853 & - & 3.8 & No & Yes \\
\hline & $\mathrm{ZnMnO}_{2}$ & 2,510 & 2,445 & 29.6 & 12.1 & Yes & Yes \\
\hline \multicolumn{2}{|c|}{ Super capacitor } & 3,412 & 2,740 & 7.0 & 4.0 & No & Yes \\
\hline \multicolumn{2}{|c|}{ CAES } & 2,292 & 2,430 & 33.1 & 12.5 & Yes & Yes \\
\hline \multicolumn{2}{|l|}{ PHS } & 1,818 & 2,166 & 34.8 & 25.0 & Yes & Yes \\
\hline \multicolumn{2}{|l|}{ SMES } & 3,974 & 3,758 & - & 1.9 & No & No \\
\hline
\end{tabular}

†“_." indicates that optimal storage size is zero. 


\subsection{Sensitivity tests for storage cost and performance parameters}

Although they have existed for decades, energy storage technologies are still experiencing relatively rapid improvements in cost and performance (e.g., [49]). As such, storage cost and performance parameters carry significant uncertainties whose impact on the overall profitability of the proposed peak shaving scheme is evaluated in several sensitivity tests below.

The U.S. Department of Energy's Office of Electricity Delivery \& Energy Reliability Energy Storage Program defined a storage capital cost target of US\$250 per kWh for NaS, Pb-acid, Li-ion, and flow batteries [49]. In our study, the average capital cost (i.e., purchase cost) for $\mathrm{NaS}, \mathrm{Pb}$-acid, Li-ion, and flow batteries ranges from US\$ 141 per $\mathrm{kWh}\left(\mathrm{ZnMnO}_{2}\right.$ battery) to US\$1,342 per $\mathrm{kWh}$ (Li-ion battery). If the target of US\$ 250 per $\mathrm{kWh}$ could be achieved in the future for Li-ion batteries ( $81 \%$ reduction versus current), the annual profit per average U.S. household could be increased by US\$ 676, or 225\% (seasonal $D L s$ ). Performance improvements of storage technologies are also underway (e.g., [50]), which would lead to higher annual profits for storage technologies. For example, for metal-air batteries, a doubling of roundtrip efficiency from $45 \%$ to $90 \%$ (achievable in the future [51]) would increase the annual profit by US\$295, or $36 \%$ (seasonal DLs).

By the same token, near term installations may not achieve the exact cost and performance parameters that represent the base case in this study, but rather storage costs may be higher and round-trip efficiencies may be lower. We therefore tested whether our conclusions remain valid with such more conservative parameters. Results are provided in Table 2. Assuming highest cost and lowest efficiencies in the literature (conservative parameters; same parameters in [21]), $\mathrm{Pb}$-acid, $\mathrm{NiCd}$, Li-ion, $\mathrm{NaS}, \mathrm{ZnBr}$ batteries, and short-term storage technologies (i.e., SMES and flywheel) would not be economically viable even when employing seasonal DLs. Annual losses range from US\$ 34 to US\$ $439(\sim 1 \%$ to $12 \%$ of the non-DR annual tariff charge). The highest profit is still achieved by PHS, which is $32 \%$ of the nonDR annual tariff charge. Note however that PHS at household-level, while not impossible, must be considered less practical [21].

Finally, we analyzed the sensitivity of our results to the installation cost and the interest rate. In Results, a US $\$ 2,000$ one-time fixed installation cost and a 10\% interest rate were assumed (basecase), resulting in a US\$ 235 fixed $L S C$ payment per year (20 years lifetime). If the installation cost were zero, flywheel and SMES would become economically viable (seasonal $D L s$ ). A more conservative assumption of the interest rate, such as $15 \%$, would increase $L S C$ (US\$ 2,000 installation cost included) by $36 \%$ (20 years lifetime). In contrast, an interest rate of 5\% would lead to $32 \%$ lower $L S C$, thus enabling higher annual profits. Storage technologies with relatively higher costs and/or lifetimes are more sensitive to the interest rate. For example, if a lower interest rate of 5\% were assumed, annual profit for PHS would change from the basecase of $39 \%$ of the non-DR annual tariff charge to $42 \%$ (seasonal $D L \mathrm{~s}$ ). But for Li-ion battery, the figures would change from $8 \%$ to $16 \%$.

In summary, we find that conservative assumptions reduce economic incentives, but many storage technologies still yield a profit (up to $32 \%$ of the non-DR annual tariff charge). In the future, expected technology improvement may enable much higher economic incentives for households. 


\subsection{Future work}

This study evaluates storage technologies only in terms of economic advantages for households. The benefits in terms of GHG emissions abatement [52-57] or air pollution reduction are not yet quantified. Emission impact analyses would be worthwhile to investigate in the future, in order to compare the emission impact incurred by different storage dispatch strategies and varying storage technologies. Furthermore, some research has developed and optimized storage dispatch strategies at the community level [58] and for multiple-unit apartments buildings [59]. Similarly, the present work may be extended to such settings as well. With regards to hardware parameters, for recent storage technologies with limited operational field experience, such as flow batteries, it is difficult to obtain accurate cost values from current literature. A best-case scenario reflecting future performance improvements (e.g., roundtrip efficiency, lifetime) and future cost reductions may be included in future work.

\section{Conclusions}

Our economic results show significant financial incentives to motivate residential consumers to install storage to shave peaks under a TOU demand tariff, using the proposed dispatch strategy. Using the same appliance demand model and storage parameters, the present peak shaving DR results in smaller optimum storage size and renders more storage technologies economically viable compared with the specific loadshifting DR as used in [21]. Annual profit without seasonal $D L$ s ranges from $-10 \%$ to $31 \%$ of the regular electricity bill (same tariff but without DR). With seasonal $D L \mathrm{~s}$, annual profits range from $-6 \%$ to $39 \%$. By utilizing a given storage capacity more efficiently, varying $D L$ across seasons makes storagebased DR generally more profitable, even rendering some technologies from unprofitable to profitable (NiCd and Li-Ion batteries). Only flywheel and SMES remain unprofitable even with seasonal DLs. Assuming conservative parameters, annual profits remain achievable but are reduced, ranging from $-12 \%$ to $32 \%$ of the non-DR electricity bill (seasonal $D L s$ ).

Note results in this study are only valid for the demand profiles of an average U.S. household (to which the agent-based demand model was calibrated) and the specific Con Edison tariff. Different demand profiles and/or tariff selections will affect achievable profits. TOU demand tariffs such as the one investigated in this study are not (yet) available in all U.S. States. Based on our results, we predict that electricity grids and household owners in other states may benefit from similar tariffs.

As shown by Hong et al. [60], weather has a significant impact on both the peak demand and energy consumption of electricity. We therefore predict that a more intelligent dispatch strategy, such as one with embedded weather forecasting capability, may result in yet higher profit.

\section{Acknowledgements}

Authors gratefully acknowledge support for the research presented herein from the National Institute of Standards and Technology (NIST), United States, grant No. 60NANB11D192. We thank Joshua Browne and Grégoire Léonard for critically reading earlier versions of this manuscript. 
Zheng et al. - APEN-D-14-05563R1 - Manuscript (no changes marked) - Page 19 of 23

\section{Nomenclature}

\begin{tabular}{|c|c|}
\hline CAES & Compressed Air Energy Storage \\
\hline DR & Demand Response \\
\hline GHG & Green House Gas \\
\hline PHS & Pumped Hydro Storage \\
\hline $\mathrm{SC}$ & Service Classification \\
\hline SD & Supplementary Data \\
\hline SMES & Superconducting Magnetic Energy Storage \\
\hline TOU & Time of use \\
\hline VRB & Vanadium Redox Battery \\
\hline ZEBRA & Sodium nickel chloride battery \\
\hline$C_{\text {installation }}$ & Installation cost (one-time parts and labor, excl. storage itself) \\
\hline$C_{\text {purchase }}$ & $\begin{array}{l}\text { Purchase cost of the storage, power conversion, and control unit combined system (excl. } \\
\text { installation), per kWh nominal capacity }\end{array}$ \\
\hline$C_{\text {tariff }}$ & Annual tariff charge \\
\hline$C_{\text {tariff, metering }}$ & Monthly metering service charge \\
\hline$C^{i, j}$ tariff, energy & Energy charge rate during month $i$ in time period $j$ \\
\hline$C^{i, j} j_{\text {tariff }}$ & Demand charge rate during month $i$ in time period $j$ \\
\hline$C_{\text {tariff, with DR }}$ & Annual tariff charge under the TOU tariff with DR \\
\hline$C_{\text {tariff, no DR }}$ & Annual tariff charge under the TOU tariff without DR \\
\hline$D L$ & Demand limit \\
\hline$E C$ & Effective capacity of storage \\
\hline$E T_{\text {tot }}$ & Total-energy-throughput \\
\hline$E T_{\text {sim }}$ & Simulated annual energy-throughput \\
\hline$L S C$ & Levelized cost of storage equipment (annualized) \\
\hline$P_{\text {appliances }}(t)$ & Power draw required by appliances at time step $t$ \\
\hline$P_{\text {grid }}(t)$ & Power draw from grid at time step $t$ \\
\hline$P_{\text {storage }}(t)$ & Storage (dis-)charge power (negative, if storage is discharged) at time step t \\
\hline$P_{\max }$ & Maximum (dis-)charge power (specified to storage technologies) \\
\hline$N C$ & Nominal capacity of storage \\
\hline $\operatorname{Pr}$ & Annual profit (tariff charge reduction from DR minus $L S C$ ) \\
\hline $\operatorname{SoC}(t)$ & St77orage state of charge at time step $t$ \\
\hline$T A C$ & Total annual cost to household \\
\hline$U^{i, j}{ }_{\text {energy }}$ & Energy usage during month $i$ in time period $j$ \\
\hline$U^{i, j}$ demand & 30 -min average maximum demand during month $i$ in time period $j$ \\
\hline$\eta_{\text {in }}$ & Ratio of electricity stored to electricity drawn from the grid by the storage \\
\hline$\eta_{\text {out }}$ & Efficiency of converting energy stored to electricity being supplied to appliances \\
\hline$\eta_{\text {DoD }}$ & Healthy depth of discharge of storage \\
\hline$\xi$ & Levelization multiplier (similar to a capital recovery rate) \\
\hline$r$ & Interest rate \\
\hline$k$ & System lifetime \\
\hline$n$ & Number of lifetime available full cycles as specified by manufactures or vendors \\
\hline
\end{tabular}


Zheng et al. - APEN-D-14-05563R1 - Manuscript (no changes marked) - Page 20 of 23

\section{References}

[1] North American Electric Reliability Corporation. 2013 Long-term reliability assessment. December 2013. http://www.nerc.com/pa/RAPA/ra/Reliability\%20Assessments\%20DL/2013 LTRA FINAL.pdf.

[2] U.S. Department of Energy. The smart grid: an introduction. 2008.

[3] Dunn B, Kamath H, Tarascon J-M. Electrical Energy Storage for the Grid: A Battery of Choices. Science. 2011;334:928-35. http://dx.doi.org/10.1126/science.1212741.

[4] White CD, Zhang KM. Using vehicle-to-grid technology for frequency regulation and peak-load reduction. Journal of Power Sources. 2011;196:3972-80.

http://dx.doi.org/10.1016/j.jpowsour.2010.11.010.

[5] Mount T. Investment performance in deregulated markets for electricity: a case study of new york

state. Prepared for the American Public Power Association. 2007.

http://www.publicpower.org/files/PDFs/StudyMountEMRIreportNYISOCapacity09-07.pdf.

[6] Balijepalli VSKM, Pradhan V, Khaparde SA, Shereef RM. Review of demand response under smart grid paradigm. Innovative Smart Grid Technologies - India (ISGT India), 2011 IEEE PES2011. p. 23643.

[7] Divya KC, Østergaard J. Battery energy storage technology for power systems-An overview.

Electric Power Systems Research. 2009;79:511-20. http://dx.doi.org/10.1016/j.epsr.2008.09.017.

[8] Hall PJ, Bain EJ. Energy-storage technologies and electricity generation. Energy Policy.

2008;36:4352-5. http://dx.doi.org/10.1016/j.enpol.2008.09.037.

[9] Chen H, Cong TN, Yang W, Tan C, Li Y, Ding Y. Progress in electrical energy storage system: A critical review. Progress in Natural Science. 2009;19:291-312.

http://dx.doi.org/10.1016/j.pnsc.2008.07.014.

[10] Skyllas-Kazacos M, Chakrabarti M, Hajimolana S, Mjalli F, Saleem M. Progress in flow battery research and development. Journal of the Electrochemical Society. 2011;158:R55-R79.

http://dx.doi.org/10.1149/1.3599565.

[11] Schoenung SM, Hassenzahl WV. Long- vs. Short-Term Energy Storage Technologies Analysis.

Sandia Report SAND2003-2783. August 2003. http://prod.sandia.gov/techlib/access-

control.cgi/2003/032783.pdf.

[12] Schoenung SM. Energy Storage Systems Cost Update. Sandia Report SAND2011-2730. April 2011. http://prod.sandia.gov/techlib/access-control.cgi/2011/112730.pdf.

[13] Callaway DS, Hiskens IA. Achieving Controllability of Electric Loads. Proceedings of the IEEE. 2011;99:184-99. http://dx.doi.org/10.1109/JPROC.2010.2081652.

[14] Zheng M, Meinrenken CJ, Lackner KS. Electricity storage in buildings for residential sector demand response: Control algorithms and economic viability evaluation. National Institute of Standards and Technology (GCR 14-978). 2014. http://dx.doi.org/10.6028/NIST.GCR.14-978.

[15] Kabir MN, Mishra Y, Ledwich G, Xu Z, Bansal RC. Improving voltage profile of residential distribution systems using rooftop PVs and Battery Energy Storage systems. Applied Energy.

2014;134:290-300. http://dx.doi.org/10.1016/j.apenergy.2014.08.042.

[16] Eyer J, Corey G. Energy Storage for the Electricity Grid: Benefits and Market Potential Assessment Guide. Sandia Report SAND2010-0815. February 2010.

http://www.sandia.gov/ess/publications/SAND2010-0815.pdf.

[17] Electric Power Research Institute. Electricity Energy Storage Technology Options: A White Paper Primer on Applications, Costs, and Benefits. Electric Power Research Institute Technical Update 1020676. December 2010. http://large.stanford.edu/courses/2012/ph240/doshay1/docs/EPRI.pdf.

[18] The Federal Energy Regulatory Commission Staff. National Action Plan on Demand Reponse. The Federal Energy Regulatory Commission Docket No AD09-10. June 2010.

http://www.ferc.gov/legal/staff-reports/06-17-10-demand-response.pdf.

[19] Department of Energy. Communications requirements of smart grid technologies. Department of Energy; October 2010. 
Zheng et al. - APEN-D-14-05563R1 - Manuscript (no changes marked) - Page 21 of 23

[20] Mokrian P, Stephen M. A stochastic programming framework for the valuation of electricity storage. 26th USAEE/IAEE North American Conference2006. p. 24-7.

[21] Zheng M, Meinrenken CJ, Lackner KS. Agent-based model for electricity consumption and storage to evaluate economic viability of tariff arbitrage for residential sector demand response. Applied Energy. 2014;126:297-306. http://dx.doi.org/10.1016/j.apenergy.2014.04.022.

[22] Kurucz CN, Brandt D, Sim S. A linear programming model for reducing system peak through customer load control programs. Power Systems, IEEE Transactions on. 1996;11:1817-24. http://dx.doi.org/10.1109/59.544648.

[23] Dlamini NG, Cromieres F. Implementing peak load reduction algorithms for household electrical appliances. Energy Policy. 2012;44:280-90. http://dx.doi.org/10.1016/j.enpol.2012.01.051.

[24] Leadbetter J, Swan L. Battery storage system for residential electricity peak demand shaving. Energy and Buildings. 2012;55:685-92. http://dx.doi.org/10.1016/j.enbuild.2012.09.035.

[25] Oudalov A, Cherkaoui R, Beguin A. Sizing and Optimal Operation of Battery Energy Storage System for Peak Shaving Application. Power Tech, 2007 IEEE Lausanne2007. p. 621-5.

[26] Lujano-Rojas JM, Monteiro C, Dufo-López R, Bernal-Agustín JL. Optimum residential load management strategy for real time pricing (RTP) demand response programs. Energy Policy. 2012;45:671-9. http://dx.doi.org/10.1016/j.enpol.2012.03.019.

[27] Shcherbakova A, Kleit A, Cho J. The value of energy storage in South Korea's electricity market: A Hotelling approach. Applied Energy. 2014;125:93-102. http://dx.doi.org/10.1016/j.apenergy.2014.03.046. [28] Byrne RH, Silva-Monroy CA. Estimating the maximum potential revenue for grid connected electricity storage: arbitrage and regulation. Sandia Report SAND2012-3863. December 2010. http://www.sandia.gov/ess/publications/SAND2012-3863.pdf.

[29] Consolidated Edison Company of New York Inc. Schedule for Electricity Service, P.S.C. No.10Electricity. 2012. http://www.coned.com/documents/elecPSC10/GR1-23.pdf [Accessed February 2012]. [30] Zheng M, Meinrenken C. Electricity demand and storage dispatch modeling for buildings and implications for the smartgrid. Bulletin of the American Physical Society 58(4), Q152. 2013. http://meetings.aps.org/link/BAPS.2013.APR.Q15.2.

[31] Meinrenken CJ, Gillespie WD, Macheret S, Lempert WR, Miles RB. Time domain modeling of spectral collapse in high density molecular gases. The Journal of Chemical Physics. 1997;106:8299-309. doi:http://dx.doi.org/10.1063/1.473893.

[32] Gillespie WD, Meinrenken CJ, Lempert WR, Miles RB. Interbranch line-mixing in CO2(1001) and (0201) combination bands. The Journal of Chemical Physics. 1997;107:5995-6004.

doi:http://dx.doi.org/10.1063/1.474268.

[33] Macheret S, Meinrenken C, Williams G, Gillespie W, Lempert W, Miles R. Radiative energy addition to high pressure supersonic air. 1996;Paper AIAA: 96-1984.

[34] Macheret S, Williams G, Comas G, Meinrenken C, Lempert W, Miles R. Energy addition and thermalization issues in a radiatively-driven hypersonic wind tunnel. 1995;Paper AIAA: 95-2142. [35] U.S. Bureau of Labor Statistics. 2012 American Time Use Survey. United Department of Labor; 2013.

[36] Jouanneau S, La Salle ALG, Verbaere A, Guyomard D. The origin of capacity fading upon lithium cycling in Li1. 1V3O8. Journal of the Electrochemical Society. 2005;152:A1660-A7.

[37] Sauer DU, Wenzl H. Comparison of different approaches for lifetime prediction of electrochemical systems - Using lead-acid batteries as example. Journal of Power Sources. 2008;176:534-46.

http://dx.doi.org/10.1016/j.jpowsour.2007.08.057.

[38] Barré A, Deguilhem B, Grolleau S, Gérard M, Suard F, Riu D. A review on lithium-ion battery ageing mechanisms and estimations for automotive applications. Journal of Power Sources.

2013;241:680-9. http://dx.doi.org/10.1016/j.jpowsour.2013.05.040.

[39] Serrao L, Chehab Z, Guezennee Y, Rizzoni G. An aging model of Ni-MH batteries for hybrid electric vehicles. Vehicle Power and Propulsion, 2005 IEEE Conference2005. p. 8 pp.

[40] Ning G, White RE, Popov BN. A generalized cycle life model of rechargeable Li-ion batteries. Electrochimica Acta. 2006;51:2012-22. http://dx.doi.org/10.1016/j.electacta.2005.06.033. 
Zheng et al. - APEN-D-14-05563R1 - Manuscript (no changes marked) - Page 22 of 23

[41] Broussely M, Herreyre S, Biensan P, Kasztejna P, Nechev K, Staniewicz RJ. Aging mechanism in Li ion cells and calendar life predictions. Journal of Power Sources. 2001;97-98:13-21.

http://dx.doi.org/10.1016/S0378-7753(01)00722-4.

[42] Sarre G, Blanchard P, Broussely M. Aging of lithium-ion batteries. Journal of Power Sources.

2004;127:65-71. http://dx.doi.org/10.1016/j.jpowsour.2003.09.008.

[43] Bindner H, Cronin T, Lundsager P, Manwell JF, Abdulwahid U, Baring-Gould I. Lifetime modelling of lead acid batteries. ISBN: 8755034411, Risø National Laboratory, Roskilde 2005.

[44] Peterson SB, Apt J, Whitacre JF. Lithium-ion battery cell degradation resulting from realistic vehicle and vehicle-to-grid utilization. Journal of Power Sources. 2010;195:2385-92.

http://dx.doi.org/10.1016/j.jpowsour.2009.10.010.

[45] Wang J, Liu P, Hicks-Garner J, Sherman E, Soukiazian S, Verbrugge M, et al. Cycle-life model for graphite-LiFePO4 cells. Journal of Power Sources. 2011;196:3942-8.

http://dx.doi.org/10.1016/j.jpowsour.2010.11.134.

[46] Schiffer J, Sauer DU, Bindner H, Cronin T, Lundsager P, Kaiser R. Model prediction for ranking lead-acid batteries according to expected lifetime in renewable energy systems and autonomous powersupply systems. Journal of Power Sources. 2007;168:66-78.

http://dx.doi.org/10.1016/j.jpowsour.2006.11.092.

[47] Guena T, Leblanc P. How Depth of Discharge Affects the Cycle Life of Lithium-Metal-Polymer Batteries. Telecommunications Energy Conference, 2006 INTELEC '06 28th Annual International2006. p. $1-8$.

[48] Meinrenken CJ, Lackner KS. Fleet view of electrified transportation reveals smaller potential to reduce GHG emissions. Applied Energy. 2015;138:393-403.

http://dx.doi.org/10.1016/j.apenergy.2014.10.082.

[49] Office of Electricity Delivery \& Energy Reliability. Energy Storage Program Planning Document.

U.S. Department of Energy; 2011.

[50] Armand M, Tarascon JM. Building better batteries. Nature. 2008;451:652-7.

http://dx.doi.org/10.1038/451652a.

[51] Girishkumar G, McCloskey B, Luntz AC, Swanson S, Wilcke W. Lithium-Air Battery: Promise and Challenges. The Journal of Physical Chemistry Letters. 2010;1:2193-203.

http://dx.doi.org/10.1021/jz1005384.

[52] Draucker L, Kaufman S, ter Kuile R, Meinrenken C. Moving Forward on Product Carbon Footprint

Standards. Journal of Industrial Ecology. 2011;15:169-71. 10.1111/j.1530-9290.2011.00331.x.

[53] Meinrenken CJ, Kaufman SM, Ramesh S, Lackner KS. Fast Carbon Footprinting for Large Product

Portfolios. Journal of Industrial Ecology. 2012;16:669-79. http://dx.doi.org/10.1111/j.1530-

9290.2012.00463.x.

[54] Meinrenken CJ, Sauerhaft BC, Garvan AN, Lackner KS. Combining Life Cycle Assessment with

Data Science to Inform Portfolio-Level Value-Chain Engineering. Journal of Industrial Ecology.

2014;18:641-51. http://dx.doi.org/10.1111/jiec.12182.

[55] Ciroth A, Meinrenken CJ. Data quality in LCAs. Environmental Life Cycle Assessment; Rita Schenk and Philip White (ed), The American Center For Life Cycle Assessment. 2014.

[56] Meinrenken CJ, Lackner KS. Carbon Hotspots in the Food and Beverage Industry: Insights from Analyzing the Product Portfolio of a Global Packaged Consumer Goods Company. Agriculture and Environmental Sciences 2014;3(4).

[57] Meinrenken CJ, Lackner KS. Options to dissociate $\mathrm{CO} 2$ and $\mathrm{H} 2 \mathrm{O}$ for sustainable sunlight-to-fuel pathways: Comparative assessment of current R\&D hurdles and future potential. Natural Sciences. 2014;2(2).

[58] Arghandeh R, Woyak J, Onen A, Jung J, Broadwater RP. Economic optimal operation of Community Energy Storage systems in competitive energy markets. Applied Energy. 2014;135:71-80. http://dx.doi.org/10.1016/j.apenergy.2014.08.066.

[59] Comodi G, Giantomassi A, Severini M, Squartini S, Ferracuti F, Fonti A, et al. Multi-apartment residential microgrid with electrical and thermal storage devices: Experimental analysis and simulation of 
Zheng et al. - APEN-D-14-05563R1 - Manuscript (no changes marked) - Page $\mathbf{2 3}$ of $\mathbf{2 3}$

energy management strategies. Applied Energy. 2015;137:854-66.

http://dx.doi.org/10.1016/j.apenergy.2014.07.068.

[60] Hong T, Chang W-K, Lin H-W. A fresh look at weather impact on peak electricity demand and energy use of buildings using 30-year actual weather data. Applied Energy. 2013;111:333-50.

http://dx.doi.org/10.1016/j.apenergy.2013.05.019. 